\title{
Optimal Control Approach For HIV-1 Infection in CD4+T Cells with RTI and PI Treatments
}

\author{
R. Heru Tjahjana and Sutimin
}

\begin{abstract}
The purpose of this paper is to expose the optimal approach of controlling HIV-1 infection in CD4+T cells with Reverse Transcriptease Inhibitors (RTI) and Protease Inhibitors (PI) treatments. The scope of the paper includes a proposed model of the dynamic system of HIV-1 infection in CD4 cells with RTI and PI as controls and a proposed objective function model that minimizes infected CD4+T Cells, the population of free virus and therapeutic costs. From the dynamics system model and objective function model, we designed an optimal control for HIV-1 infection control. In this paper, we obtained optimal control for RTI and PI therapies. The results of this paper are as follows: by using the optimal control approach, we obtained infectious control strategy that minimizes actively infected CD4+T Cells, the population of free virus and the cost of treatment. In other words, optimal control is a good approach in determining infection control strategies that minimizes the objective function.

Index Terms-CD4+T Cells, RTI, PI, HIV-1 Infection.
\end{abstract}

\section{INTRODUCTION}

A CQUIRED Immunodeficiency Syndrome (AIDS) is caused by HIV infection, one of the dangerous diseases that leads to death. In Indonesia, based on the report from the Ministry of Health, until March 31st, 2016, there are more than 13,200 people died from AIDS, 198.219 people are infected by HIV and 78,292 people are infected by AIDS. From the data, $53 \%$ of the infection are transmitted among heterosexuals and it is the highest group getting HIV infection. Many researchers are interested in studying HIV infection.

The study about HIV infection was conducted by Srivastava et al. They considered incomplete Reverse Transcription (RT) of HIV life cycle in CD4+ T cells and the effect of RTI drug to block the infection of CD4+ T cells [1]. Elaiw developed a model to capture HIV infection regarding the interaction of virus with both $\mathrm{CD} 4+\mathrm{T}$ cells and macrophage and studied the behavior of global stability of equilibriums for the dynamical model due to the effect of antiretroviral treatment [2]. Tarfulea proposed a mathematical model taking into account the effect of combined RTI and PI drug classes to capture the dynamical behavior of HIV infection. It shows that the adherence level in taking drug determine the progress of HIV infection. The combination of RTI and PI treatments become a better treatment than that of monotherapy of RTI or PI, and drug resistance increases viral load in the body [3]. Perelson and Ribeiro used a simple model to reveal the quantitative findings

Manuscript received January 20, 2020; accepted May 19, 2020.

The authors are with the Department of Mathematics, Diponegoro University, Semarang, 50275 Semarang (corresponding author to provide phone and fax: 024-76480922; E-mail: heru.math.undipe gmail.com). This research was supported by RPI Diponegoro University. of HIV biology for acute HIV infection, drug response and the emergence of viral variants [4]. Chirove et al. developed a host model to capture the spread of HIV-1 infection that is transmitted from free virus interaction to target cells and contact of infected cells to healthy cells. Chirove et al. also took into account Langerhans target cells in the mathematical model. The infection among target cells take place due to the interaction between virus and target cells, and the interaction between infected cells and susceptible target cells. The results show that the progress of HIV infection is determined by the critical values of virus production by infected CD4+ T cells. Other results show that the infection cycles in the infection process are obtained [5]. Meanwhile, Sutimin et al. developed a model taking into account the combination effect of RTI and PI drugs to block the HIV-1 infection. The drug response of target cells depends on the characteristic of immune cells, thereby the immune system of each individual shows different drug response. In the model, they divided Langerhans and CD4+ T cells into sub classes namely: sub class containing the active drugs and subclass which is not acquiring drugs [6], [7]. Sutimin et al. developed and analyzed a mathematical model incorporating the infection process through cell to cell contact of CD4+T cells, CTL compartment and the combination of RTI and PI treatments [8].

\section{The Proposed Model}

In this section, the proposed mathematical model is explained in detail. The mathematical model is developed from [1], [6], [7]. In [1], Sivastava et al. did not incorporating cellcell viral transmission. In [6], [7], although considering cellcell transmission but in the studies did not taken into account incomplete reverse transcription in latent infection of CD4+ T cells. In the proposed model, we incorporate viral transmission both through cell-to-cell and the effect of incomplete reverse transcription in latent infection of $\mathrm{CD} 4+\mathrm{T}$ cells. The mathematical model introduced the interaction between the infected CD4+ $\mathrm{T}$ cells and healthy $\mathrm{CD} 4+\mathrm{T}$ cells, virus clearance by $\mathrm{CD} 4+\mathrm{T}$ cells, and the effect of PI drug in blocking the viral replication in infected CD4+ T cells. The complete model consists of two models. The first model is a dynamical model and the second one is a model of objective function. The dynamical model describes the spread of HIV-1 infection within host cells and the objective functional model describes minimization of infected CD4+T Cells, the population of free virus and the cost of therapy. 
The proposed dynamical model can be presented as follows

$$
\begin{aligned}
\frac{d T}{d t} & =\lambda-\mu_{t}-\beta_{1} V T-\beta_{2} V T+\left(\varepsilon_{R T I} \alpha+\rho\right) T_{1}, \\
\frac{d T_{1}}{d t} & =\beta_{1} V T+\beta_{2} V T-\left(\mu_{1}+\alpha+\rho\right) T_{1}, \\
\frac{d T_{i}}{d t} & =\left(1-\varepsilon_{R T I}\right) \alpha T_{1}-\left(\mu_{t}+\delta\right) T_{i}, \\
\frac{d V}{d t} & =N \delta\left(1-\varepsilon_{P I}\right) T_{i}-\mu_{v} V-\phi V T .
\end{aligned}
$$

The proposed objective function model that must be minimized is

$$
J=\int_{t_{0}}^{t_{f}}\left(C_{1} T_{i}+C_{2} V+w_{1} \varepsilon_{R T I}^{2}+w_{2} \varepsilon_{P I}^{2}\right) d t .
$$

Consider (1), the populations of susceptible CD4+ T cells symbolized by $T$ die with the constant rate $\mu_{t}$. The recruitment rate of CD4+ T cells can be denoted by $\lambda$. The population is infected by free virus and CD4+ T cells with the constant rate $\beta_{1}$ and $\beta_{2}$, respectively. Sometimes, viruses enter into CD4+ T cell and Reverse Transcription (RT) takes place in cytoplasm. The symbol $T_{1}$ is incomplete RT CD4+ T cells and may return to susceptible with the constant rate $\rho$. Once the cells acquire active RTI drug, it returns to healthy with the rate $\alpha$ due to the effectiveness of drug. The population diminishes due to the natural death with the constant rate $\mu_{t}$. The symbol $T_{i}$ represents CD4+ T cells that take place complete RT, thereby it is called the actively infected CD4+ $\mathrm{T}$ cells. These population diminish due to the natural death and lysis at the constant rate $\mu_{t}, \delta$, respectively, and the infection rate of the population in class $T_{1}$ reduces to $\left(1-\varepsilon_{R T I}\right) \alpha$ due to the effectiveness of RTI drug. The population of free virus $V$ is produced by the infected $\mathrm{CD} 4+\mathrm{T}$ cells with the average of the virus number decreases to $\left(1-\varepsilon_{P I}\right) N \delta$ due to the effect of PI treatment, and diminishes due to natural death and clearance at the constant rates $\mu_{v}$ and $\phi$, respectively. The constant $N$ and $\mu_{t}$ are the average number of virions produced by infected $\mathrm{CD} 4+\mathrm{T}$ cells and the constant natural death rate of CD4+ T cells, respectively. In control theory, model (1) consists of 4 state variables and two control variables. The state variables are $T, T_{1}, T_{i}$ and $V$. The control variables are $\varepsilon_{R T I}$ and $\varepsilon_{P I}$.

The values of the parameters used in this paper can be seen in Table I.

The parameter values used in this paper are based on estimation and data of HIV sufferers from the laboratory as reported in the paper referenced. For parameter values according to the reference values are in an interval, estimated by taking one value in the interval. Another reason why this paper takes parameter values such as those used in the next simulations is because recent papers on HIV-1 [6], [7], [8] also refer to those values. With the explanation regarding the development of the model at the beginning of Section II and the reasons for taking the values of the parameters above, it can be said that the proposed model is a valid model.

\begin{tabular}{|c|c|c|c|c|}
\hline Parameters & Values & Descriptions & Units & Source(s) \\
\hline$\lambda$ & 10 or 20 & $\begin{array}{l}\text { Production rate } \\
\text { of CD4+ T cells }\end{array}$ & Cells/day & [9] \\
\hline$\phi$ & $(2,9)$ & $\begin{array}{l}\text { Constant } \\
\text { degradation rate } \\
\text { by Langerhans } \\
\text { cells }\end{array}$ & 1/day & {$[10],[11]$} \\
\hline$\beta_{1}$ & 0.0001 & $\begin{array}{l}\mathrm{CD} 4+\mathrm{T} \text { cells in- } \\
\text { fection rate by } \\
\text { free virus }\end{array}$ & 1/day & [12], [13] \\
\hline$\beta_{2}$ & 0.00015 & $\begin{array}{l}\mathrm{CD} 4+\mathrm{T} \text { cells } \\
\text { infected rate by } \\
\mathrm{CD} 4+\mathrm{T} \text { cells }\end{array}$ & $1 /$ day & [5] \\
\hline$\delta$ & 0.2 & $\begin{array}{l}\text { Constant lysis } \\
\text { death rate of } \\
\text { infected CD4+T } \\
\text { cells }\end{array}$ & 1/day & [9] \\
\hline$\alpha$ & 0.26 & $\begin{array}{l}\text { Transmission rate } \\
\text { of T1 due to in- } \\
\text { complete the RT }\end{array}$ & 1/day & [1] \\
\hline$\mu_{t}$ & 0.01 & $\begin{array}{l}\text { Natural death } \\
\text { rate of CD4+ T } \\
\text { cells }\end{array}$ & 1/day & [14] \\
\hline$\mu_{v}$ & 2.40 & $\begin{array}{l}\text { Natural death } \\
\text { rate of free virus }\end{array}$ & 1/day & [15] \\
\hline$\mu_{1}$ & 0.015 & $\begin{array}{l}\text { Natural death } \\
\text { rate of CD4+ } \\
\mathrm{T} \text { cells due to } \\
\text { inflammation }\end{array}$ & 1/day & [16] \\
\hline$\rho$ & 0.025 & $\begin{array}{l}\text { Constant rate } \\
\text { from incomplete } \\
\text { RT class to } \\
\text { healthy CD4+ T }\end{array}$ & 1/day & [1] \\
\hline$N$ & $(100,1000)$ & $\begin{array}{l}\text { The average } \\
\text { number r of } \\
\text { virions produced } \\
\text { by infected } \\
\text { CD4+T cells }\end{array}$ & $\begin{array}{l}\text { Virions/ } \\
\text { cells } \\
\text { day }\end{array}$ & $\begin{array}{l}\text { [17], } \\
\text { [18], [19] }\end{array}$ \\
\hline
\end{tabular}

\section{MathematicAl ANALYSis}

In this section, controllability analysis and the existence of optimal control is reported. In control theory, dynamical model
TABLE I: Values of the Parameters

(1) is nonlinear control system. The controllability analysis of the model (1) presented in the Theorem 1 as follows.

Theorem 1: The dynamical model (1) is locally accessible

Proof: The proof starts from change the form of model (1) to Affine system. In Affine system form, model (1) has a drift. The next step is generate controllability matrix through Lie Bracket. After check the rank of controllability matrix and the result is full rank, so we can conclude that the model (1) is locally accessible.

After controllability analysis, the next analysis is existence of optimal control. The existence of optimal control can be exposed in Theorem 2 as follows.

Theorem 2: Optimal control problem with dynamical model (1) and objective function (2) exist.

Proof: The proof is based on the convexity of each summand in objective function (2). Since each summand is convex and summation of convex function is also convex then the objective functional (2) is convex. If the objective function (2) is convex then the solution of optimal control problem exists. 


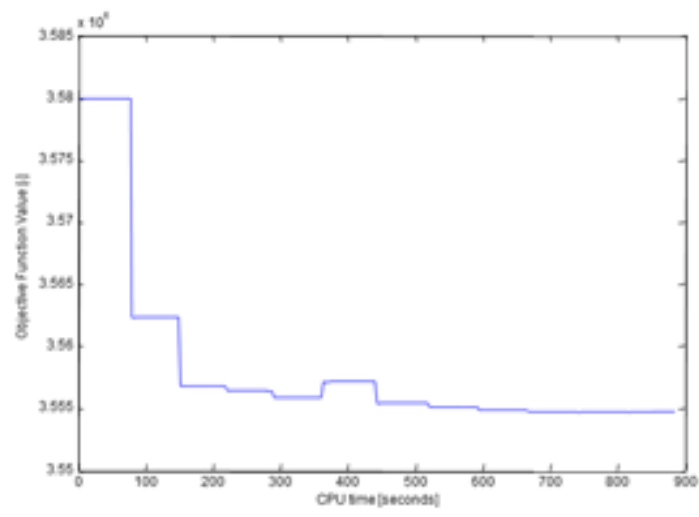

Fig. 1: Values of objective function.

\section{Simulation Results}

Besides values of the parameters, another important thing in the simulation is determination of initial condition $T(0), T_{1}(0)$, $T_{i}(0)$ and $V(0)$. The process of control design for simulation, starts from dynamical model (1). The values of the parameters from Table I are subtituted in (1) and (2), so we have a system of differential equations. With the system of differential equations and objective functional (2), the Hamiltonian function is obtained. After Hamiltonian function, the Hamiltonian system is obtained. Next, the Pontryagin Maximum Principle is used to compute the optimal condition for each control variables. Therefore, the equation for each control variable is obtained. Then, each control variable is subtituted to the Hamitonian system and we have the ordinary differential equation system with control variable which has been substituted. The simulation result is obtained from this ordinary differential equation system with initial values for $T(0), T_{1}(0), T_{i}(0)$ and $V(0)$ are $850,0,41$ and 3.76, respectively. The initial and final times, namely 0 and 70 , respectively.

In this paper, the numerical method used to solve the ordinary differential equation system numerically is RungaKutta method. The computation is performed using the Matlab software. The Matlab version used to make simulations is Matlab R 2008a.

The main result of simulation can be described in Fig. 1 and Fig. 2 as follows. The values of objective function $J$ and control variables $u_{1}$ and $u_{2}$ are plotted in Fig. 1 and Fig. 2, respectively.

Considering objective function (2), as described in Section II, the objective of this paper is to minimize the objective cost. Trend of objective function value is decreasing as can be seen in Fig. 1. The plot of simulation to minimize the objective function shows this trend. Plot of objective function in Fig. 1 indicates that efforts to minimize objective functions have been seen, although the functional plot of $J$ is seen to increase at a time interval of about 350 to 450 increased compared to the value of the function at the previous interval of 150 until 345. This is possible because there are values in functional costs whose value rises at the time in that interval. Next, after 450 , it can be seen that the trend of the value of $J$ looks to continue to decreased.

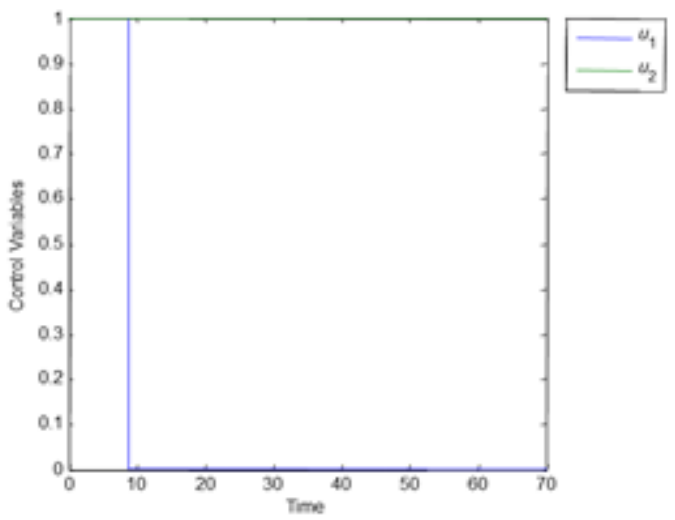

Fig. 2: Plot of controls versus time.

Subsequent simulations are $u_{1}$ and $u_{2}$. As the objective of this paper, it is to find the optimal strategy through optimum control for 70 days, for each of the minimum $u_{1}$ and $u_{2}$, the simulation result is shown in Fig. 2. It is noted that the objective function (2), besides minimizing $J$, the main objective of this paper is to determine how the minimum possible $u_{1}$ and $u_{2}$ can minimize the objective function value. Since $u_{1}$ represents the cost of RTI and $u_{2}$ represents the cost of PI, and it is only natural that these costs are the matters that must be minimized. Plot of $u_{1}$ and $u_{2}$ versus time can seen in Fig. 2.

\section{CONCLUSiOnS}

With the optimal control approach, optimal control for RTI and PI treatments can be found that they simultaneously minimize functional objectives. The mathematical model for the spread of HIV-1 infection is within the host cells of four nonlinear differential equations. From the dynamics model (1) and objective function (2), with the optimal control approach, it can be obtain the simulation results of minimizing objective functional value and simulation of control determination for the minimum RTI and PI. The results are reproduced in plots $u_{1}$ and $u_{2}$ throughout the initial and final times, namely 0 and 70. For the record, different parameter values can provide plot results that may not be the same as the simulation plot results. However, the values of parameters taken from these references in the source make a convincing result for the reader. From Fig. 1, it can be seen that the value of objective function can be minimized. From Fig. 2, the minimization $u_{1}$ and $u_{2}$ was successfully shown.

\section{ACKNOWLEDGMENT}

This work was financially supported by the Diponegoro University under the International Scientific Publication Research Grant. The authors thank to the reviewers for the valuable comments to improve the quality of this paper.

\section{REFERENCES}

[1] P. Srivastava, M. Banerjee, and P. Chandra, "Modeling the drug therapy for hiv infection," Journal of Biological Systems, vol. 17, no. 02, pp. 213-223, 2009 
[2] A. Elaiw, "Global properties of a class of hiv models," Nonlinear Analysis: Real World Applications, vol. 11, no. 4, pp. 2253-2263, 2010.

[3] N. Tarfulea, "A mathematical model for hiv treatment with time-varying antiretroviral therapy," International Journal of Computer Mathematics, vol. 88, no. 15, pp. 3217-3235, 2011.

[4] A. Perelson and R. Ribeiro, "Modeling the within-host dynamics of hiv infection," BMC biology, vol. 11, no. 1, p. 96, 2013.

[5] F. Chirove, Sutimin, E. Soewono, and N. Nuraini, "Analysis of combined langerhans and cd $4 \hat{+} \mathrm{t}$ cells hiv infection," SIAM Journal on Applied Mathematics, vol. 74, no. 4, pp. 1174-1193, 2014.

[6] Sutimin, F. Chirove, E. Soewono, N. Nuraini, and L. Suromo, "A model incorporating combined rtis and pis therapy during early hiv-1 infection," Mathematical biosciences, vol. 285, pp. 102-111, 2017.

[7] S. Sutimin, N. Nuraini, F. Chirove, and L. Suromo, "Modelling multiple dosing with drug holiday in antiretroviral treatment on hiv-1 infection," Journal of Mathematical and Fundamental Sciences, vol. 49, no. 1, pp. 1-17, 2017.

[8] S. Sutimin, S. Sunarsih, and R. Tjahjana, "Modeling cd4+ t cells and ctl response in hiv-1 infection with antiretroviral therapy," Communication in Biomathematical Sciences, vol. 1, no. 2, pp. 100-109, 2018.

[9] R. Culshaw and S. Ruan, "A delay-differential equation model of hiv infection of cd4+ t-cells," Mathematical biosciences, vol. 165, no. 1, pp. 27-39, 2000.

[10] A. Perelson and P. Nelson, "Mathematical analysis of hiv-1 dynamics in vivo," SIAM review, vol. 41, no. 1, pp. 3-44, 1999.

[11] A. Perelson, A. Neumann, M. Markowitz, J. Leonard, and D. Ho, "Hiv-1 dynamics in vivo: virion clearance rate, infected cell life-span, and viral generation time," Science, vol. 271, no. 5255, pp. 1582-1586, 1996.

[12] D. Kirschner, "Using mathematics to understand hiv immune dynamics," Notices of the AMS, vol. 43, no. 2, pp. 191-202, 1996.

[13] Z. Wang and X. Liu, "A chronic viral infection model with immune impairment," Journal of Theoretical Biology, vol. 249, no. 3, pp. 532 542, 2007.

[14] M. Stafford, L. Corey, Y. Cao, E. Daar, D. Ho, and A. Perelson, "Modeling plasma virus concentration during primary hiv infection," Journal of theoretical biology, vol. 203, no. 3, pp. 285-301, 2000.

[15] A. Perelson, D. Kirschner, and R. De Boer, "Dynamics of hiv infection of cd4+ t cells," Mathematical biosciences, vol. 114, no. 1, pp. 81-125, 1993.

[16] A. Kamath, S. Henri, F. Battye, D. Tough, and K. Shortman, "Developmental kinetics and lifespan of dendritic cells in mouse lymphoid organs," Blood, The Journal of the American Society of Hematology, vol. 100, no. 5, pp. 1734-1741, 2002.

[17] B. Adams, H. Banks, M. Davidian, H.-D. Kwon, H. Tran, S. Wynne, and E. Rosenberg, "Hiv dynamics: modeling, data analysis, and optimal treatment protocols," Journal of Computational and Applied Mathematics, vol. 184, no. 1, pp. 10-49, 2005.

[18] D. Dimitrov, R. Willey, H. Sato, L.-J. Chang, R. Blumenthal, and M. Martin, "Quantitation of human immunodeficiency virus type 1 infection kinetics." Journal of virology, vol. 67, no. 4, pp. 2182-2190, 1993.

[19] A. Haase, K. Henry, M. Zupancic, G. Sedgewick, R. Faust, H. Melroe, W. Cavert, K. Gebhard, K. Staskus, Z.-Q. Zhang, P. Dailey, H. Balfour Jr., A. Erice, and A. Perelson, "Quantitative image analysis of hiv-1 infection in lymphoid tissue," Science, vol. 274, no. 5289, pp. 985-989, 1996. 